\title{
Teorias espaciais contemporâneas: o conceito de competitividade sistêmica e o paradigma da sustentabilidade ambiental
}

\section{Contemporany spacial theories: the concept of competitiveness and the paradigm of environmental sustainability}

\author{
Luis Lopes DINIZ FILHO ${ }^{1}$ \\ Yara VICENTINI ${ }^{2}$
}

\begin{abstract}
RESUMO
O artigo aborda paradigmas da utopia ambiental da cidade sustentável, discutindo as definições de sustentabilidade, aliada à transferência economicista do termo competitividade, entendendo que as estratégias de desenvolvimento devem pautar-se em progressivos investimentos para a obtenção de melhores índices de qualidade de vida, conforme indicadores internacionais. Trata da assimilação de modelos definidos para grandes capitais mundializadas, em realidades diferenciadas na miséria metropolitana do terceiro mundo. Nesses termos, aos paradigmas presentes nas propostas de reorganização espacial e produtiva do território, assim como nas reformas urbanas contemporâneas em curso nas cidades mundiais, não correspondem possibilidades de investimento e renda geral da população na América Latina, resultando em assimilações incompletas de políticas de gestão urbana ou em cenários mal acabados de projetos urbanos.

Palavras-chaves: sustentabilidade, competitividade e cidades e meio ambiente.
\end{abstract}

\begin{abstract}
This paper deals with broaches the paradigms of the environmental utopia of the sustainability cities, arguing about the sustainability concept, allied with the economicist transference of the term competitiveness, understanding that development strategies must support themselves in progressive investiments on achieving better life quality indicators, based on internacional levels. It treats about the
\end{abstract}

1 Prof. Dr. do Depto de Geografia e do Programa de Mestrado em Geografia da UFPR.

2 Profa. Dra. do Depto de Arquitetura e Urbanismo e do Programa de Doutorado em Meio Ambiente e Desenvolvimento da UFPR, bolsista produtividade CNPq 
DINIZ FILHO, L. L.; VICENTINI, Y. Teorias espaciais contemporâneas: o conceito de competividade...

assimilation of models defined to world cities, in differing realities in the third world metropolitan misery. This way the paradigms of spacial and productive territory reorganization proposals, just like on the contemporary urban reforms going on the global cities, do not correspond to the possibilities of investment and general incoming of the Latin America population, resulting in incomplete assimilations of urban management policies or in badly finished urban projects scenaries.

Key-words: sustainability, competitiveness, city environment.

\section{Introdução}

A idealização racionalista da cidade, que definiu o pensamento sobre a Técnica e a Razão nas Teorias Espaciais Urbanas e Regionais, expõe a discussão sobre a reprodução da cidade racionalista e seus desdobramentos contemporâneos, como tendência de reinterpretação dos princípios do urbanismo funcionalista aliado à competição entre cidades, regiões e nações.

O plano da cidade moderna, como idealização social, esteve alinhado às teorias urbanísticas conhecidas como urbanismo moderno internacional ou racionalismo e que foram definidas pelos Congressos Internacionais de Arquitetura Moderna - (CIAMS) que se desenvolveram de 1928 a 1956, como explanam Frampton (1995) e Torres (1996).

No núcleo básico da teoria, apresentava-se um modelo analítico de abordagem urbanística baseado em uma categorização rígida das funções urbanas, com a separação de cada uma delas em seu domínio territorial, o zoneamento. De fins da década de 20 até o início da década de 40, a aplicação desses princípios a casos urbanos concretos engendraram a realização de um conjunto de planos reguladores, como princípios teóricos de propostas de intervenções urbanas efetivadas.

Mas foi só após o término da guerra que as formulações puderam ser colocadas em prática, em compasso com a construção de novas cidades que seguissem os princípios do racionalismo funcionalista. Por outro lado, as idealizações modernistas também propunham uma atuação pela transformação do tecido urbano, por meio de planos reguladores, zoneamento urbano por uso e ocupação do solo e códigos de edificação, conjunto de interpretações teóricas da cidade moderna que foram adotados em diferentes contextos.

Os "Planos Diretores", que foram concebidos no período do pós-guerra, foram produções que ampliaram os métodos empíricos na concepção abstrata da cidade-um tipo de urbanismo que herda, metodologicamente, os princípios racionalistas, adotando etapas de interpretação do espaço urbano, por meio de suas propostas de análise, diagnóstico, proposições e aplicações, como também a crença nas virtudes do zoneamento, com a separação das funções urbanas e o pressuposto de que estas se estruturam conforme um modelo hierárquico no espaço. $\mathrm{O}$ impacto deste urbanismo aliado à filosofia e à prática administrativa do planejamento britânico, em particular com o exemplo do Plano de Londres de 1945, conduziu, inexoravelmente, as teorias espaciais a um pragmatismo.

Nessa direção, a partir da segunda metade da década de 60, surgem transformações importantes no quadro dos instrumentos (analíticos, matemáticos, empíricos) que até então haviam se configurado com a transformação das escalas de abordagem que abandonam o espaço urbano e suas teorizações, para abarcar, ao gosto das teorias espaciais do território, as denominadas áreas metropolitanas. Nessa medida, o planejamento pragmático inglês vai competir com o planejamento racionalista.

É, portanto, nos países de mais forte tradição de intervenções urbanas, que têm lugar alterações em relação às suas concepções e instrumentos e às escalas de intervenções. O autor Torres (1996) discute como os termos "estratégico" e "esquema" são adotados na Inglaterra, com a Estratégia do Sudeste, em 1976, e na França com o termo Esquema Diretor para a região parisiense, em 1965, posteriormente atualizado em 1969 e 1976. Apontam para o objetivo de influenciar as macroestruturas urbanas, com grandes investimentos públicos em transporte e equipamentos, considerando as cidades novas construídas nesse período. Em especial na França, como coloca Topalov (1988), assiste-se a um reviver do velho ideal reformista, com a preconi-zação de uma modernização social realizada pelo planejamento do território e liberada do peso da política.

A partir da década de 80 , esse quadro de discussão sobre o urbano e as áreas metropolitanas e seu papel articulador de uma rede de cidades vai colocar-se de forma diferenciada, com a mundialização da economia e a caracterização das cidades globais, que vai condicionar um processo de transformação metropolitana e a maior participação dos governos locais, conforme expõem diferentes autores. 
DINIZ FILHO, L. L.; VICENTINI, Y. Teorias espaciais contemporâneas: o conceito de competividade...

Assiste-se a um desmonte das instituições metropolitanas e o desenvolvimento de grandes empreendimentos urbanos que se constituem em planos de intervenções pontuais de grande impacto sobre a imagem urbana, em uma perspectiva formal e simbólica, que reforça a imagem urbana e vem sendo denominado de Plano Estratégico. Segundo Harvey (1992), cessam os esforços para o desenvolvimento de modelos de planos urbanos oriundos das matrizes modernistas, substituídos pela adoção de estratégias pluralistas e orgânicas na abordagem do desenvolvimento urbano, como uma colagem de espaços e misturas formais. Ao invés de planos baseados no zoneamento funcional de diferentes atividades, tornam-se importantes os temas específicos do lugar e as localizações especiais da nova economia de serviços na cidade.

O mesmo autor afirma que as alterações dos patamares tecnológicos do mundo industrial contemporâneo subvertem a lógica da cidade moderna com o aumento da densidade, alterações e diversidade de usos comuns, a reinterpretação e confusão entre os espaços públicos e privados e as subjetividades de uma nostalgia individualizada, gerando amplas reformas urbanas e a inversão de paradigmas e concepções territoriais. A metrópole, tão celebrada pelo modernismo, aponta para espaços urbanos pulverizados, concentração em áreas suburbanas, redes caracterizadas não mais pelo mote da produção industrial concentrada, mas por redes tecnológicas de informação e recortes ambientalistas de preservação e prevenção no uso dos recursos naturais nas cidades mundiais de países desenvolvidos.

Essas redes são, agora, transnacionais e representam investimentos acelerados de renovação urbana, mesmo que possam parecer, em análises precipitadas, o fim das idéias do urbanismo. Ao contrário, mesmo considerando o anacronismo de alguns megaprojetos urbanos, indigestos em relação às discussões de restauração, preservação, reabilitação e imagem, seu descolamento em relação ao plano da cidade, como de um plano para a sociedade, caracterizam a realidade presente a ser compreendida e discutida. (VICENTINI, 2001).

Foram os autores Lefebvre (1976) e Castells (1977), entre outros, que engendraram, a partir da década de setenta, as análises de mais de uma geração de teóricos da cidade, vinculando o desenvolvimento estrutural da teoria marxista aos processos de acumulação e ao Estado em seu papel redistribuidor do capital social amealhado.

Já para o período contemporâneo, a perplexidade coloca-se perante o contexto da produção contemporânea do espaço, com a redefinição de uma estratégia de atuação no espaço urbano "neoconservadora" que propõe políticas públicas que reforcem o poder político de grupos restritos e lugares beneficiados pelo novo entendimento da desconcentração, variando em sua heterogenia de desconcentração nos subúrbios americanos em torno de shopping centers, ou da aplicação do darwinismo social nas denominadas áreas em depressão nas cidades latino-americanas. Ou como se afirmou:

Neste sentido, as grandes reformas urbanas contemporâneas nas cidades mundiais, definitivamente exclu-dentes da população urbana não mais pertencente ao corpo do mundo do trabalho ou do consumo, parte dos pressupostos de um novo urbanismo, com o desenho arbitrado da cidade - comunidade, uma cultura de animação, sem senso ou modelo plausível de uma modernidade e de um humanismo recorrente. Ao planejamento colocam-se novas fórmulas de sustentabilidade e competitividade. Na periferia do mundo globalizado (não mais a periferia de um capitalismo progressivo), na direção da discussão atenta de Maricato (1996), um misto de exclusão e promiscuidade dos interesses públicos e privados, com arremedos de soluções contemporâneas sem caráter. (VICENTINI, 2001)

Castells e Borja (1996) apresentam argumentos em que são expostos os parâmetros do Plano Estratégico, segundo o qual as cidades são analisadas como atores políticos e sociais complexos, como cidades no interior do processo de globalização, elas mesmas atuando no sentido de promoção de acordos e associações, como núcleo central de articulação entre a sociedade civil, a iniciativa privada e as instâncias do Estado. A propagação desses pressupostos, o "Projeto Cidade", vem ganhando expressão significativa em várias cidades européias e latino-americanas, bem como o novo caráter das formulações espaciais regionais, que, da matriz anterior de pólos de desenvolvimento, passa a um recorte regional competitivo, com todas as caracterizações que o termo pode suscitar.

Nessa direção, interessa discutir como o paradigma econômico regional, que na história recente do planejamento estava territorialmente pautado em redes de produção, é substituído por abordagens de redes de infra-estrutura com enfoque ambiental, as quais reservam às cidades capitais o papel do Projeto Cidade. 
DINIZ FILHO, L. L.; VICENTINI, Y. Teorias espaciais contemporâneas: o conceito de competividade...

Ao mote ambiental, que dá origem às definições de sustentabilidade, alia-se a transferência economicista do termo competitividade, entendendo que as estratégias de desenvolvimento devem pautar-se em progressivos investimentos para a obtenção de melhores índices de qualidade de vida, conforme indicadores internacionais. Restringese à assimilação de modelos definidos por temáticas em grandes capitais mundializadas, para realidades diferenciadas na miséria metropolitana do terceiro mundo.

\section{Planejamento regional contemporâneo: a apro- priação dos termos competitividade sistêmica e sustentabilidade ambiental}

Uma das características do ambiente político-ideológico contemporâneo é o elevado grau de homogeneidade dos diagnósticos e propostas encaminhadas para a resolução dos problemas sociais e econômicos, o que representa uma das facetas do atual contexto de globalização da economia. A análise dos discursos sobre o desenvolvimento revela de modo claro que existe ampla convergência de diagnósticos e propostas também nessa área, inclusive no que tange às políticas de desenvolvimento regional, que tomam como pressupostos básicos para a elaboração de diagnósticos e estratégias os conceitos de competitividade sistêmica e de desenvolvimento sustentável (DINIZFILHO, 1999).

Nesse sentido, é importante fazer algumas considerações teóricas e metodológicas sobre o conceito de competitividade sistêmica, no intuito de melhor compreender as características do novo modelo de planejamento urbano e regional que emergiu nos anos 90. Com efeito, a crescente complexidade dos sistemas produtivos e a intensificação da concorrência capitalista, ocasionadas pelo contexto da globalização e da Terceira Revolução Industrial e
Tecnológica, teve pelo menos dois reflexos importantes na ciência econômica dos últimos vinte anos. ${ }^{3} \mathrm{O}$ primeiro deles foi o fortalecimento da idéia segundo a qual a competitividade das empresas não depende apenas de fatores microeconômicos, mas também de todo o ambiente macroeconômico, político-institucional e até cultural em que as empresas atuam. O segundo reflexo importante, derivado do primeiro, foi a elaboração de teorias que procuram demonstrar que o desenvolvimento econômico nacional é função da competitividade das empresas, no sentido de que os países que apresentam crescimento econômico mais acelerado e renda per capita elevada são aqueles que hospedam empresas altamente competitivas nos mercados em que operam, sobretudo quando se trata de mercados internacionalizados.

Nesse contexto, as teorias de desenvolvimento baseadas no conceito de competitividade sistêmica diferem das teorias de matriz neoclássica na medida em que, ao invés de buscarem construir modelos matemáticos que possam explicar o desenvolvimento econômico com base nas relações entre um pequeno número de fatores determinantes, procedem à identificação de um grupo bastante amplo de fatores que condicionam a competitividade das empresas e os classificam segundo esquemas lógicos que procuram revelar as complexas formas de interação entre esses fatores.

Esse procedimento aparece de forma clara nos conhecidos estudos de Michael Porter sobre o tema, no qual o autor afirma a centralidade do "panorama nacional" na determinação da competitividade das empresas e, mediante a sistematização dos resultados de dezenas de estudos de caso sobre as indústrias de dez países bastante diferentes, chega a um sistema classificatório baseado em "quatro amplos atributos que modelam o ambiente no qual as empresas competem e que promovem (ou impedem) a criação da vantagem competitiva" ( PORTER, 1993, p. 87). Segundo esse modelo, tais atributos são:

\footnotetext{
3 Embora o termo "globalização" seja usado geralmente para designar um processo central da atualidade, os estudos que dele se utilizam acabam quase sempre analisando uma série de processos muito heterogêneos, nem sempre relacionados entre si. Mesmo os trabalhos que circunscrevem a discussão dentro de um campo mais específico (como a Economia ou a Geografia) reconhecem que há inúmeros processos que podem ser designados pela noção de globalização. Daí porque autores como Baumann (1996) e Coutinho (1992) apontam a fragilidade dessa noção, que, por se referir a um conjunto muito heterogêneo de fenômenos, acaba se tornando vaga demais para constituir um conceito. Há também problemas relativos às confusões entre essa noção e outras que lhe são semelhantes (como a de "transnacionalização"), bem como à questão de determinar até que ponto a globalização poderia constituir alguma novidade histórica de fato (BECKER, 1999, p. 13). Por essa razão, talvez fosse mais profícuo pensar a globalização não como um processo, mas sim como uma nova etapa da "espacialidade capitalista" (CORRÊA, 1997, p. 189). Assim, a globalização pode ser pensada como um estágio qualitativamente novo da internacionalização do capitalismo, caracterizado pela ação de uma série de processos que, embora muito distintos entre si, convergem de modo a reduzir a autonomia política dos Estados nacionais e de requalificar suas funções econômicas (BECKER, 1991, p. 53), e lembrando que parte desses processos convergentes diz respeito aos impactos das novas tecnologias sobre a organização dos sistemas produtivos, que passam a se integrar de forma cada vez mais internacionalizada.
} 
DINIZ FILHO, L. L.; VICENTINI, Y. Teorias espaciais contemporâneas: o conceito de competividade...

1. Condições de fatores: Dizem respeito aos fatores de produção que afetam a competitividade das indústrias em função da qualidade e quantidade da oferta nacional. Engloba desde os recursos naturais e a oferta de mão-de-obra, passando pelas infra-estruturas básicas de transportes, energia e telecomunicações, até os equipamentos de infraestrutura mais sofisticados, tais como centros de pesquisa e universidades.

2. Condições de demanda: Envolvem as características da demanda nacional para os produtos ou serviços de uma indústria. Até mesmo elementos culturais, como o valor simbólico atribuído a determinados bens de consumo conspícuo, afetam a competitividade das indústrias ligadas à produção desses bens, na medida em que eleva a exigência dos consumidores com relação à qualidade.

3. Indústrias correlatas e de apoio: A presença ou não, no país, de indústrias fornecedoras e de apoio que sejam internacionalmente competitivas, sendo que o autor define as indústrias de apoio como “(...) aquelas em que empresas podem partilhar atividades na cadeia de valores através das indústrias (por exemplo, canais de distribuição, desenvolvimento de tecnologia) ou transferir conhecimentos protegidos pelo direito de propriedade de uma indústria para outra. Um exemplo de três indústrias correlatas é a de carros, caminhões leves e empilhadeiras (usadas para manuseio do material dentro e fora de fábricas e armazéns)" (PORTER, 1993, p. 150).

4. Estratégia, estrutura e rivalidade das empresas: As condições jurídico-institucionais, culturais e econômicas que definem o modo pelo qual as empresas de um país são criadas, organizadas e dirigidas, bem como a natureza da competição entre as empresas no mercado interno.

A esses quatro determinantes da vantagem competitiva das nações (que atuam de forma mutuamente fortalecedora), Porter acrescenta ainda dois elementos que afetam positiva ou negativamente a competitividade das empresas de uma nação. O primeiro deles é o papel do "acaso" na história das empresas que lograram assumir a liderança competitiva internacional, visto que eventos totalmente fortuitos, tais como guerras, crises do petróleo ou rupturas tecnológicas podem beneficiar ou prejudicar for- temente as trajetórias das empresas. O segundo elemento é o papel do governo, na medida em que as políticas nacionais afetam os determinantes da vantagem competitiva das empresas.

O governo tem importante influência sobre a vantagem competitiva nacional, embora seu papel seja inevitavelmente parcial. A política governamental falhará se continuar sendo a única fonte de vantagem competitiva nacional. As políticas bem-sucedidas funcionam nas indústrias onde os determinantes subjacentes da vantagem nacional estão presentes e onde o governo os reforça. O governo, ao que parece, pode apressar ou aumentar as probabilidades de obter vantagem competitiva (e vice-versa), mas falta-lhe o poder de criar a própria vantagem (PORTER, 1993, p. 148).

Nesse contexto, nota-se que o modelo teórico elaborado por Michael Porter atribui ao Estado um papel bem mais limitado na criação de condições de competitividade do que outros trabalhos que se dedicam a esse tema. No modelo elaborado pelo Instituto Alemão de Desenvolvimento (IAD), fica claro que as políticas estatais atuam em quase todos os quatro "níveis" de determinantes da competitividade sistêmica, conforme se pode verificar neste breve resumo do modelo mencionado (ESSER et al., 1994):

1. Nivel Macro: Engloba as políticas macroeconômicas propriamente ditas, como as políticas cambial, monetária e fiscal, além da política de comércio exterior (pautada pela integração ativa da economia nacional aos mercados internacionais) e das políticas voltadas para a regulação da concorrência entre as empresas, as quais devem impedir a formação de monopólios e cartéis.

2. Nível Micro: Os fatores de competitividade ligados exclusivamente à organização interna das empresas, às estratégias empresariais e às relações inter-empresas. Envolve assim a capacidade de gestão, a aplicação de best practices em todas as etapas do ciclo de produção (desenvolvimento de produtos, produção propriamente dita e comercialização), a gestão da inovação, a integração em redes de cooperação tecnológica, a logística empresarial e a interação entre provedores, produtores e usuários.

3. Nivel Meta: Conjunto de fatores que compreende: a) a formação de um consenso social em tor- 
DINIZ FILHO, L. L.; VICENTINI, Y. Teorias espaciais contemporâneas: o conceito de competividade...

no da necessidade de uma política econômica voltada para o mercado mundial; b) “(...) um padrão básico de organização jurídica, política, econômica e macrossocial que permita aglutinar as forças dos atores, potencializar as vantagens nacionais de inovação, crescimento econômico e competitividade, e colocar em marcha processos sociais de aprendizagem e comunicação" (ESSER et al., 1994, p. 1); c) por fim, “(...) a disposição e a capacidade de implementar uma estratégia de médio a longo prazo com vistas ao desenvolvimento tecnológico-industrial orientado à competitividade" (ESSER et al., 1994, p. 1).

4. Nível Meso: Diz respeito, na maior parte, à organização do espaço em que estão inseridas as empresas, à dotação de fatores de produção desses espaços e às políticas implementadas para intervir na organização espacial e na dotação de fatores, como: a política de infra-estrutura física, que abarca os sistemas de transporte, energia e telecomunicações; a política de infra-estrutura industrial; a política educacional, que visa a melhorar a qualificação da mão-de-obra; e por fim as políticas ambientais e regionais. Adicionalmente, este nível de determinantes da competitividade abrange as políticas seletivas de importação e de exportação.

Como se pode verificar, o modelo do IAD difere daquele elaborado por Michael Porter na medida em que coloca as políticas públicas (inclusive as políticas ambientais e regionais) entre os determinantes da competitividade das empresas. A própria definição e classificação dos determinantes da competitividade em cada modelo já demonstra como a visão de Porter possui um caráter liberal, na medida em que enfatiza a importância da empresa como unidade de análise fundamental, enquanto o IAD analisa a questão com maior ênfase nos aspectos sociais, que incluem a ação do Estado e a mobilização da sociedade. Perspectiva semelhante à do IAD pode ser encontrada no conceito de competitividade que serve de base ao Estudo da Competitividade da Indústria Brasileira (ECIB), até hoje a pesquisa de maior alcance realizada no país sobre o tema, conforme segue:

A competitividade pode ser vista como a produtividade das empresas ligada à capacidade dos governos, ao com- portamento da sociedade e aos recursos naturais e construídos, e aferida por indicadores nacionais e internacionais, permitindo conquistar e assegurar fatias do mercado" (COUTINHO; FERRAZ, 1994, p. 10).

No intuito de dar inteligibilidade aos inúmeros determinantes da competitividade e suas relações mútuas, o ECIB elaborou um modelo de classificação baseado em três categorias:

1. Fatores internos à empresa: Equivale ao "nível micro" do modelo do IAD, pois diz respeito aos fatores que estão sob controle direto das empresas e que são administrados com vistas a estabelecer diferenças em relação aos competidores. A capacidade de criar e ampliar "vantagens competitivas" é de grande importância para o desempenho de uma empresa.

2. Fatores estruturais: São controlados pelas empresas apenas parcialmente e definem o "ambiente competitivo" em que elas atuam. Esse conjunto de fatores abarca as características dos mercados consumidores, a "configuração da indústria em que a empresa atua" (grau de concentração e de verticalização, escalas de operação, atributos dos insumos, relações com fornecedores, usuários e concorrentes, etc.) e, por fim, a natureza da concorrência, que diz respeito às "regras que definem condutas e estruturas empresariais em suas relações com consumidores, meio ambiente $\mathrm{e}$ competidores", o sistema tributário e fiscal, etc. (COUTINHO; FERRAZ, 1994, p. 20).

3. Fatores sistêmicos: Compreendem todo o conjunto de "externalidades stricto sensu para a empresa produtiva", as quais podem ser: macroeconômicas, político-institucionais; reguladoras, como por exemplo as políticas de propriedade intelectual e de preservação do meio ambiente; infraestruturais; sociais (condições da mão-de-obra, política educacional, legislação trabalhista e de seguridade social, bem como o grau de exigência dos consumidores); internacionais, como as tendências do comércio mundial e dos fluxos de capitais, etc.; last but not least, os "fatores referentes à dimensão regional", que envolvem os aspectos associados à distribuição espacial das atividades produtivas. 
DINIZ FILHO, L. L.; VICENTINI, Y. Teorias espaciais contemporâneas: o conceito de competividade...

Portanto, todos os trabalhos mencionados utilizam essencialmente o mesmo método classificatório de análise, diferindo substancialmente apenas no que tange à decisão de incluir ou não as políticas públicas entre os fatores responsáveis pela competitividade das empresas. Nesse sentido, não seria correto associar as políticas públicas calcadas no conceito de competitividade sistêmica à corrente de pensamento econômico neoliberal, com suas propostas em prol de um "Estado mínimo". O ECIB, por exemplo, constrói suas propostas de políticas públicas a partir de críticas enfáticas ao modelo neoliberal, utilizando-se justamente da análise dos fatores estruturais e sistêmicos da competitividade como base dessa crítica.

Especificamente sobre o espectro de políticas enfocadas neste texto, é preciso ressaltar que foi justamente por conta da ênfase na natureza sistêmica do fenômeno da competitividade e do desenvolvimento que as teorias pautadas pelo conceito de competitividade sistêmica acabaram, muito rapidamente, por ser assimiladas no âmbito do planejamento econômico regional.

De fato, embora tais teorias estivessem primordialmente interessadas em explicar as diferenças de desenvolvimento entre países, é fácil perceber que muitos fatores de produção importantes para a competitividade das empresas se expressam espacialmente em escala regional, como se nota na localização de recursos naturais importantes para determinados setores de atividade, nas diferenciações espaciais da oferta e qualidade das infra-estruturas e também na dimensão e diversificação dos mercados de consumo e de mão-de-obra presentes nas grandes aglomeraçõesurbanas.

Por tais razões, o conceito de competitividade sistêmica apresenta necessariamente uma dimensão geográfica, na medida em que trata das inter-relações entre inúmeros fatores de produção que possuem expressão espacial e que ocorrem em escalas variadas, que vão do regional ao global. Mas há ainda outro aspecto das teorias de desenvolvimento contemporâneas que impõe uma abordagem geográfica e que acabou por ser assimilado ao conceito de competitividade, e que é a questão ambiental.

Com efeito, já não é possível pensar a questão do desenvolvimento de forma desvinculada da questão ambiental nos dias atuais, ao contrário do que ocorria nos debates da Economia do Desenvolvimento e da Geografia Econômica até o final dos anos 60. Nessa época, o termo "desenvolvimento" era compreendido praticamente como sinônimo de crescimento econômico, mas o agravamento da ques- tão ambiental e a persistência de problemas sociais e desigualdades gritantes em inúmeras regiões do globo levaram à concepção de que o desenvolvimento é um processo multidimensional, que só pode ser compreendido a partir de um enfoque capaz de englobar aspectos socioeconômicos, políticos, culturais e ambientais (DINIZFILHO, 2000).

Como parte dessa mudança de perspectiva, o fortalecimento dos sistemas jurídico-institucionais de regulamentação e fiscalização das práticas ambientais das empresas, bem como as diferenciações nacionais quanto ao ritmo desse processo, fez com que as questões ambientais tivessem necessariamente que fazer parte das análises pautadas pelo conceito de competitividade sistêmica. De um lado, nota-se a existência de empresas que, aproveitandose de legislações nacionais permissivas e/ou de sistemas fiscalizadores débeis, ampliam sua competitividade de forma espúria, mediante o rebaixamento dos custos de produção com base em práticas ambientalmente predatórias; de outro lado, empresas que se mostram capazes de se adaptar com eficiência a sistemas regulatórios e fiscalizadores rígidos podem transformar essa capacidade em vantagem competitiva, na medida em que a questão da sustentabilidade ambiental dos processos produtivos vem sendo incorporada à regulamentação do comércio internacional e às políticas de financiamento dos grandes bancos.

Nesse contexto, as políticas regionais elaboradas ao longo dos anos 90, no Brasil e no exterior, tomam como pressupostos fundamentais para a elaboração de diagnósticos e estratégias de desenvolvimento os conceitos de competitividade sistêmica e de desenvolvimento sustentável (DINIZ FILHO, 2002; BOISIER, 1994). Fica claro, portanto, que os conceitos de desenvolvimento sustentável e de competitividade sistêmica (sobretudo o primeiro) condensam em si mesmos tudo o que é desejável no contexto dos valores predominantes na sociedade contemporânea, além de pressuporem a possibilidade de harmonizar as diversas dimensões do desenvolvimento (econômica, social, ambiental e espacial). A diferença entre os dois conceitos é que, enquanto o "desenvolvimento sustentável” enfatiza a compatibilização entre crescimento econômico acelerado e conservação ambiental, a "competitividade sistêmica" dá ênfase, sobretudo, à integração competitiva das estruturas produtivas regionais ao mercado internacional como condição para acelerar o desenvolvimento econômico e a geração de emprego e renda. Contudo, não existe nenhuma teorização que $\mathrm{p}$ ermita assegurar a possibilidade 
DINIZ FILHO, L. L.; VICENTINI, Y. Teorias espaciais contemporâneas: o conceito de competividade...

de harmonizar essas múltiplas dimensões do desenvolvimento de forma a priori, sem falar nas próprias ambigüidades e incertezas que cercam o conceito de desenvolvimento sustentável.

Todavia, se a análise realizada até o momento deixa claro que os condicionantes da competitividade se expressam e se articulam espacialmente em escalas geográficas diferenciadas, sendo por isso objetos do planejamento nacional, regional e ambiental, fica ainda em aberto a questão de determinar se haveria a possibilidade de pensar o desenvolvimento da competitividade sistêmica segundo um ponto de vista urbano, ou melhor, como objeto de intervenção do planejamento urbano.

De outra forma, o enfoque ambiental também passa a expressar a temática e meta de desenvolvimento urbano, metropolitano e regional e tem sido assimilado por diferentes contextos, em uma difusão sem precedentes de um novo modo de planejar. Não se trata de um modelo de intervenção hegemônico, mas de um modelo de descentralização da gestão acrescido de políticas públicas sociais, econômicas e ambientais de âmbito regional e urbano. Surge como uma alternativa ao sistema de planos setorizados, como uma nova estratégia de formulação de políticas com instrumentos autônomos da administração para o processo de desenvolvimento. Constitui-se em um megaprojeto de recuperação ambiental, que se expressa por extensivos investimentos de saneamento em busca da qualidade socioambiental e seu recorte territorial passa a configurar, preferencialmente, bacias e sub-bacias hídricas.

Nesse entendimento, as conceituações hoje enfatizadas - como Metrópole Competitiva, Sustentável e Solidária - são desfocadas, abarcando para um discurso construído a partir de itens controversos, que pertencem a matrizes teóricas diversas e que são apresentados como coerentes e concorrentes, mas que representam, a priori, definições políticas e institucionais não convergentes - confusão de conceitos e teorias na base da assimilação de modelos mundiais.

O conceito de região torna-se, portanto, difuso na sua não-caracterização e na sua confusão metodológica, desembocando rapidamente para os velhos enfoques setoriais que não deram conta do desenvolvimento sustentável por mais de quatro décadas no Brasil.

A discussão atenta de Santos (1992), na busca da compreensão teórica da questão, destaca a natureza como uma permanência, agora compreendida como meio ambiente em uma proposta humanizada pelo homem. Conformeo autor, a realidade da industrialização produziu uma dimensão social da natureza na qual as concentrações urbanas tornaram-se o ambiente natural do homem, em expressões necessárias à reprodução e viabilização de sua estratégia e que se apresentam encobertas pela naturalização do tema. Por sua vez, a naturalização do tema produz o fechamento do universo de locução como condição para padronizar o humano - o urbano como ambiente natural torna-se o ambiente natural do urbano.

Nessa medida, o discurso do desenvolvimento sustentável, em suas construções metodológicas, não expressa de forma convincente os interesses de grupos sociais em conflito, como afirma Leff (2001). Se o homem naturalizou o ambiente, na generalização da problemática socioambiental decorrente, construída sobre diferentes matizes disciplinares, não conseguiu estabelecer uma priorização de caráter econômico que garantisse a inclusão social tão almejada.

A dificuldade assinalada é recorrente na compreensão das teorias urbanas contemporâneas frente à formulação de novas políticas e programas urbanos. Durante todo o século XX, os modelos e teorias urbanas e regionais transferidos e apreendidos pelo modo de planejar no Brasil, demonstraram sua fragilidade perante uma análise mais detalhada, expondo dificuldades de assimilação do caráter social e político destes, como já discutiu amplamente Arantes (1998). Novamente nos deparamos com tal situação, mesmo que colocada em outros termos.

Enfrentando a dicotomia estabelecida entre um modelo estratégico de planejamento das cidades mundiais, incluindo todos os ingredientes referenciais contemporâneos de volta ao urbanismo do local, perante a questão latino-americana das grandes cidades e seus espaços consolidados por décadas de exclusão, a consecução de novos modelos de gestão urbana e regional, em uma nova matriz de acordos sociais, torna inerente mudanças profundas e não previstas nos modelos econômicos em pauta.

\section{Conclus̃̃es}

Acredita-se que o desenvolvimento metodológico exposto conclui sobre a diversidade das tendências contemporâneas de abordagem das cidades mundiais. Também enfatiza que essas tendências não são homogêneas ou hegemônicas e decorrem do pensamento pós-guerra sobre as teorias urbanas, no processo de construção da crítica à cidade funcionalista. 
DINIZ FILHO, L. L.; VICENTINI, Y. Teorias espaciais contemporâneas: o conceito de competividade...

Identifica-se uma linha teórica e metodologia existente em cada uma das correntes analisadas, todas vinculadas a um processo histórico e cultural inerente. Quando reinterpretadas e transpostas, soam como simulacro ou são inviabilizadas por um contexto diverso, que, no atual processo de remodelação econômica mundial, exclui parcelas das nações da possibilidade de uma readequação das cidades como um bem estratégico, remodelando esse bem para formas de concentração em níveis de consumo mais sofisticados ou de serviços pós-industriais, como fruto de um pensar histórico, cultural e tecnológico.

\section{REFERÊECIAS}

ARANTES, O. Urbanismo em fim de linha. São Paulo: Nobel/ Edusp, 1998.

. O lugar da arquitetura depois dos modernos. São Paulo: Studio Nobel, 1993.

BAUMANN, Renato. Uma visão econômica da globalização. In: __ (Org.). O Brasil e a economia global. Rio de Janeiro: Campus, 1996.

BECKER, Bertha K. Por um redescobrimento do Brasil. In: CASTRO, Iná E.; EGLER, Claudio A. G.; MIRANDA, Mariana (Orgs.). Redescobrindo o Brasil: 500 anos depois. Rio de Janeiro: Bertrand Brasil; Faperj, 1999.

BOISIER, Sergio. Crisis y alternativas en los procesos de regionalización. Revista de La Cepal, n. 52, 1994.

BORNHEIM, G. A invenção do novo. In: NOVAES, Adauto (Org.). Tempo e história. São Paulo: Secretaria de Cultura/ Companhia das Letras, 1992.

CACCIARI, Massimo; TAFURI, Manfredo; DAL CO, Francesco. De la Vanguardia a la Metropoli. Barcelona: Gustavo Gilli, 1979.

CASTELLS, M. European cities, the informational society and the global economy. New Left Review, n. 204, p. 18-32, mar./ abr. 1994.

CASTELLS, M.; BORJA, Jordi. As cidades como atores políticos. Novos Estudos CEBRAP, São Paulo, n. 45, p. 152-166, jul. 1996.

CASTELLS, Manuel. La ciudad informacional: tecnologias de la información, reestruturación economica y el proceso urbano-regional. Madri, Espanha: Alianza Editorial, 1995.
Nesses termos, aos paradigmas presentes nas propostas de reorganização espacial e produtiva do território, assim como nas reformas urbanas contemporâneas em curso nas cidades mundiais, não correspondem possibilidades de investimento e renda geral da população na América Latina, resultando em assimilações incompletas de políticas de gestão urbana ou em cenários mal acabados de projetos urbanos. Em realidade, as grandes cidades brasileiras necessitam de investimentos em infra-estrutura básica e em políticas populares de recuperação da qualidade de vida urbana.
CORRÊA, Roberto Lobato. Trajetórias geográficas. 1. ed. Rio de Janeiro: Bertrand Brasil, 1997.

COUTINHO, Luciano G. A terceira revolução industrial e tecnológica: as grandes tendências de mudança. Economia $e$ Sociedade, n. 1, 1992.

COUTINHO, Luciano G.; FERRAZ, João Carlos (Coords.). Estudo da competitividade da indústria brasileira. 2. ed. Campinas: Papirus; Universidade Estadual de Campinas, 1994.

DINIZ FILHO, Luis Lopes. O novo paradigma de planejamento regional no Brasil dos anos 90: renovação do discurso e imobilismo do Estado. 54 REUNIÃO ANUAL DA SBPC, 54., 2002, Goiânia. Anais... Goiânia, 2002.

. A dinâmica regional recente no Brasil: desconcentração seletiva com "internacionalização" da economia nacional. 2000. Tese (Doutorado) - Departamento de Geografia da FFLCH, USP.

Notas sobre o planejamento regional brasileiro no contexto da globalização econômica e da descentralização do estado. Caderno LAGHUR, 1999.

ESSER, Klaus et al. Competitividad sistémica: competitividad internacional de las empresas y políticas requeridas. Berlim: Instituto Alemán de Desarrollo, 1994. (Série "Estudios e Informes")

FERNÁNDEZ, R. Modos de hacer ciudad. Buenos Aires: UBA/FAUD UNMdP, 1996.

FRAMPTON, K. História crítica de la arquitectura moderna. Barcelona: GG, 1987.

GOTTDIENER, M. A produção social do espaço urbano. Tradução: G. G. de Souza. São Paulo: Edusp, 1993. 
DINIZ FILHO, L. L.; VICENTINI, Y. Teorias espaciais contemporâneas: o conceito de competividade...

HABERMAS, J. O discurso filosófico da modernidade. Lisboa: Publicações Dom Quixote, 1990.

. A arquitetura pós-moderna. Dossiê Habermas, Novos Estudos Cebrap, São Paulo, n. 18, 1987.

HARVEY, David. Condição pós-moderna. São Paulo: Loyola, 1992.

LEFEBVRE, H. O pensamento marxista e a cidade. Lisboa: Ulisséia, 1972.

LEFF, Enrique. Epistemologia ambiental. São Paulo: Cortez, 2001.

MARICATO, E. Metrópole na periferia do capitalismo. São Paulo: Hucitec, 1996.
MONTANER, J. M. Después del movimiento moderno arquitectura de la segunda mitad del sigli XX. Barcelona: GG, 1993.

PORTER, Michael E. A vantagem competitiva das nações. Rio de Janeiro: Campus, 1993.

RANDOLPH, R. Determinações estratégicas e potencialidades de transformação do programa favela-bairro. Rio de Janeiro: Ippur, 1996. (fotoc.)

SANTOS, M. 1992: a redescoberta da natureza. Estudos Avançados, São Paulo, v. 6, n. 14, jan./abr. 1992.

VICENTINI, Y. Teorias da cidade: reformas contemporâneas. Desenvolvimento e Meio Ambiente, Curitiba, n. 4, 2001. 